\title{
Advantages of Using Technology to Teach English Language in Multicultural Classrooms.
} (Albanian Case)

\author{
PhD. Cand. Arti Omeri \\ Department of English Language and Literature, \\ Faculty of Philology and Education \\ Bedër University, Tirana, Albania \\ artomeri@hotmail.com \\ aomeri@beder.edu.al
}

\begin{abstract}
In recent years technology has had a huge impact on all aspects of life. As such the education would not be an exception. Albania like the rest of European countries has tried to keep in touch with the introduction of new technologies in education. The Albanian government has been very ambitious to implement the new technologies in all its public schools and universities across the country. The intended success was not a simple task to be achieved due to several factors. As a result in some public educational institutions there is still a lack of technology. In many others, especially in private institutions lecturers and teachers make full use of technology. This research is focused on the advantages that such technology has brought in teaching English language in multicultural classrooms in Albania. Results from different point of views will be discussed in the study. There was also conducted a survey in some Albanian universities to measure the impact and the role that the new technology has played since its introduction. There were 15 questions in the questionnaire that was conducted in private and public universities. The answers will be evaluated and analyzed accordingly in order to consider the advantages that this process has brought in our country. The study is important as it will try to find out not only the level of success but also the difficulties that must be very carefully dealt and analyzed in order to find the better ways to improve the situation.
\end{abstract}

Keywords: Internet, Computer, Technology, E-mail, Multicultural classroom, English teaching, Education.

\section{Introduction}

Teaching and learning English language is becoming a worldwide trend and necessity. According to Cook, G. (2003, P. 25 ) in addition to its four hundred millions of first language speaker, and over a billion people who live in a country where it is an official language, English is now taught as the main foreign language in almost every country, and used for business, education, and access to information by the majority of the world's population. Albania is one of the countries where English is the main foreign language. Children start to take English courses at school since the third class. In order to graduate from high school, students should pass an English test which is one of the three obligatory state Matura exams. The other two are math and literature. Furthermore master and $\mathrm{PhD}$ students should take one of the internationally recognized English tests in order to get their diploma.

So English is on the focus of the Albanian education system starting from primary school until PhD level. In this study there are considered techniques and devices being used to achieve good results and meet the required criteria for the language aquirement at university level. The technology being used to support it is also taken into consideration. Along with English language there are serious attempts to introduce a modern technology in universities. In her visit in a public university, published on the ministry of education website (4th April, 2014), the Albanian minister of Education Lindita Nikolla declared that "In order for us to become part of global market and in order to compete with their requirement, we should move fast forward and should invest a lot in technology of information and communication, not only in infrastructure but also in human resources." 
Furthermore prime minister of Albania, Edi Rama introduced a new project which will be first implemented in high school (Shqiptarja.com $7^{\text {th }}$ April, 2015). Through this project in 60 high schools the education process will be facilitated with the help of tablets.

Technology and English language education are related to each other (Singhal, 1997). A few decades ago language had only a human aspect. Nowadays things are changing and computers are being used to process language. There is a subfield of linguistics called Computational linguistics that is concerned with the interactions of human language and computers and includes the analysis of written texts and spoken discourse, the translation of text and speech from one language into another, the use of human (not computer) languages for communication between computers and people, and the modeling and testing of linguistic theories. (Fromkin, V., Hyams. N, Rodman R. 2011, P 391).

Zekaj (2011, P. 14) underlines that for an effective learning we should understand clearly and in depth the environment that we are in but also the outside environment, including the whole world. Actually by using technology in teaching someone reduce to a minimum level the cultural and ethnic differences in class. The only means to communicate in real time with the rest of the world is undoubtedly the technology. Through communication we can better understand other cultures and ethnicities. So by using technology in teaching someone reduces the cultural and ethnic differences not only in class but also outside it. Furthermore Zekaj (2011 P. 43) suggests that nowadays teaching is based on students characteristics and that influences the learning process. So, in order to have an effective teaching those differences should be analyzed and taken into consideration. As Kuri \& Zekaj advise in order draw or improve new programs one should know his audience (2011, P. 108). The same opinion is supported by Capella-Santana (2003, P. 188) claiming that multicultural attitudes and knowledge can be changed positively during a teacher preparation program

There are several factors that emphasize the importance of multicultural communication between students in education. Some of these factors include;

1. The open nature of communication

2. The increasing trend of emigration

3. Protecting other cultures diaspora

4. Taking into consideration the specific of children coming from ethnically mixed families.

5. The facts of the existence of cultural and linguistic discrimination

(Zekaj, Xh. Hodaj,M. Vrapi, E, 2014, P. 158).

\section{Method}

This research was conducted in two universities, in a public and a private university. The reason for that was to see this issue from two different points of view. Having the opportunity to teach in both "BEDER" (private) and "Aleksander Xhuvani" (public) universities gave me the possibility to conduct such a survey. A questionnaire composed of 15 questions was prepared and distributed to the first and second year students of the English language and literature and education department. There were asked similar questions in both universities including open ended and closed ended questions. They varied from question requiring information about the sort of technology in the class, whether this technology is being used and the opinions and suggestions of the students in order to improve the teaching and learning process. The ethnic and language background of the students was also required even though the questionnaire was anonymous. Also there were asked questions about the advantages of using technology in multicultural classrooms. First there are analyzed the specifics of both universities where the research was conducted.

Beder is a heterogeneous university located in Tirana. There are students coming from at least 16 different countries. Furthermore its academic staff comes from eight different countries giving the university a clear international aspect. It is almost impossible to find a homogenous class at Beder. This means that teaching English in such an environment is a real challenge. It is a new university and compared to Albanian standards it is considered a modern university.

On the other hand "Aleksander Xhuvani" is almost entirely a homogeneous university. English language and literature is an exception there as it sometimes attracts foreign students who mainly work or live in Albania. It is one of those universities where Albanian government has invested a lot in recent years to improve the infrastructure and technology. All the faculties have reconstructed their premises and the university is supported with new technology. 
So comparison of two universities with different characteristics would be very interesting to analyze. It gives us the possibility to contrast the technology used in public and private universities and the effects of technology in teaching English in multicultural classrooms.

\section{Results}

When asked about the sort of technology present in the class $80 \%$ of students at Beder were satisfied and all of them mentioned many devices such as smart board, projectors, tablets, computers, mobile phones, internet, emails etc. Students at "Aleksander Xhuvani" university also mentioned some devices such as computers and projectors even though their level of satisfaction was lower, around $60 \%$. Another difference is the quantity, location and access to devices. In private university they can find and use them in each single class whereas in public university they are very limited and access to them is also very limited.

An interesting finding was the frequency of using the technological devices while teaching English. Nearly $90 \%$ of students at Beder answered always or very often to that question whereas students at the public university did the opposite. The vast majority of them, $80 \%$ said that either they never use them or use them very rarely.

There were no surprises about the ethnic and language background of the students. Nearly $40 \%$ of Students at Beder who filled the questionnaires were foreigners coming from seven different countries. At "Aleksander Xhuvani" only a couple of students were of different ethnic origin.

When asked about the advantages of using technology in multicultural classes many students from both universities considered it as a tool for equality in the class. It erases possible cultural and ethnic differences and helps students who are not part of the dominant culture. So all students can see the same visuals or listen to the same accent of English language. The foreign students at private university were the ones who were asking for a greater use of technology in the class. Some of them claim that technology can easily integrate them with the rest of the class. Albanian students of public university also required a greater access to technology. They regard English as the language of technology so they should use technology to learn English and vice versa. By so doing they can close the cultural gap within the class or anywhere else in this globalized word.

\section{Discussion}

As we saw from the results of the questionnaire students value as important the use of technology in teaching English in multicultural classes. They see it as a tool that gives equal access to English studying despite the ethnic and language background of the students. Albania has made a great progress in installing a new technology and especially computers and internet in all its universities. This can make students of different ethnic background feel equal and secured in the class. It guarantees that Albanian language does not influence the English language teaching classes. Private universities seem to be a step ahead in this regard as their technological infrastructure is developing at the same pace as other European universities. That is seen as an advantage by foreign students who are now choosing to study in several private universities in Albania.

Public universities also have access to technology but they still have various difficulties. The number of computers and other technological devices are limited and are difficult to access. Usually they are kept in a room or two that most of the time are inaccessible by students or academic staff. Such devices should be distributed in a way that everyone can access them. Even in classes where there found computers they are very rarely used. They are either neglected or the staff is not properly trained how to use them. Students in the public university consider English as the language of technology. In this regard learning English through technology is an advantageous situation as they can better learn the language and at the same time improve their computer skills. Even though they might have few students of different ethnic origin in the class they see technology as the best means to eradicate those differences. Moreover they do not see the class as a concept of a room. In a larger globalized world the technology can help them to communicate in English with the rest of the world.

\section{Conclusion}


Technology development has brought significant innovations in English language teaching. Albania has tried to keep in touch with such a trend. The increasing number of foreign students studying in Albanian universities is demanding more technological devices. There have been large investments on public universities to improve the situation. On the other hand private universities have already built a comfortable ad modern infrastructure. It has had a positive impact in English teaching and students' satisfaction. In multicultural classrooms the teaching and learning process is greatly influenced by digitalization of universities and the introduction of a modern technology. Even though there are still many difficulties encountered mainly at public universities. The number of technological devices should keep increasing and they should be accessible to anyone seeking to use them.

Since those technologies have only recently been introduced in Albanian universities there is a lack of knowledge how to operate and use them. The Albanian government simultaneously with the process of digitalization should also introduce and encourage training programs for lecturers and students. The universities should stay up to date with recent developments in technology and multicultural classes. Multicultural programs should be designed and they should be implemented in the class through the new technology.

\section{Bibliography}

[1] Capella-Santana, N, (2003) Voices of Teacher Candidates: Positive changes in Multicultural Attitudes and Knowledge, The Journal of Educational Research, Vol. 96, No. 3.

[2] Cook, G. (2003). Appied Linguistics. Oxford Uniiversity Press

[3] Fromkin, V., Hyams. N, Rodman R. (2011). An Introduction to Language.Wadsworth Cengage Learning.

[4] http://shqiptarja.com/m/home/--39-shkollat-dixhitale--39--nga-shtatori--60-gjimnaze-m-sim-me-tableta283771.html, 7th April, 2015.

[5] http://www.arsimi.gov.al/al/newsroom/lajme/investimi-ne-inovacion-nje-investim-per-te-ardhmen\&page=20 Ministria e Arsimit dhe Sportit, 4prill, 2014.

[6] Journal, 3(6). Retrieved from http://iteslj.org/Articles/Singhal-Internet.html

[7] Kuri, V. \& Zzekaj, Xh (2011), Sjellja Organizacionale e Liderit “Formimi i menaxherit dhe Drejtimi i Shkolles".

[8] Singhal, M. (1997). The internet and foreign language education: Benefits and challenges. The Internet TESL

[9] Zekaj, Xh. (2011). Bazat e procesit mesimor. Shtepia Botuese "Kristal".

[10] Zekaj, Xh. Hodaj,M. Vrapi, E, (2014). Komunikimi Pedagogjik. Shtypur ne “Julvin 2'. 